\title{
Direct Recording of Nicotinic Responses in Presynaptic Nerve Terminals
}

\author{
Jay S. Coggan, Jacques Paysan, William G. Conroy, and Darwin K. Berg \\ Department of Biology, 0357, University of California, San Diego, La Jolla, California 92093-0357
}

\begin{abstract}
Nicotinic acetylcholine receptors are widely expressed in the nervous system, but their functions remain poorly understood. One attractive hypothesis is that the receptors act presynaptically to modulate synaptic transmission. We provide a direct demonstration of presynaptic nicotinic receptors in situ by using whole-cell patch-clamp techniques to record currents in large presynaptic calyces that midbrain neurons form on ciliary neurons. Bath application of nicotine induced inward currents in the calyces capable of generating action potentials that overrode the limited space clamp achievable. The inward currents reversed near $0 \mathrm{mV}$ and showed inward rectification common for neuronal nicotinic receptors. Tetrodotoxin (TTX) blocked the action potentials but not the inward currents. $\alpha$-Bungarotoxin blocked both, consistent with the presynaptic receptors containing $\alpha 7$ subunits. Recording from the postsynaptic ciliary neurons during nicotine exposure revealed EPSCs that TTX blocked, presumably by blocking presynaptic action potentials. The postsynaptic cells also displayed bimodal
\end{abstract}

inward currents caused by their own nicotinic receptors; the bimodal currents were not blocked by TTX but were blocked partially by $\alpha$-bungarotoxin and completely by $\mathrm{D}$-tubocurarine. Dyefilling with Lucifer yellow from the recording pipette confirmed the identity of patched structures and showed no dye transfer between calyx and ciliary neuron. When calyces or ciliary neurons were labeled en mass with neurobiotin and biocytin through nerve roots, dye transfer was rarely observed. Thus, electrical synapses were infrequent and unlikely to influence calyx responses. Immunochemical analysis of preganglionic nerve extracts identified receptors that bind $\alpha$-bungarotoxin and contain $\alpha 7$ subunits. The results unambiguously document the existence of functional presynaptic nicotinic receptors.

Key words: nicotinic receptor; receptors; acetylcholine; presynaptic; preganglionic; ciliary ganglion; neuronal; $\alpha 7$; $\alpha$-bungarotoxin; patch-clamp; modulation; transmitter release
Nicotinic acetylcholine receptors (AChRs) are cation-selective ligand-gated ion channels that are widely expressed throughout the vertebrate nervous system (for review, see Sargent, 1993; McGehee and Role, 1995). Despite their similarities to muscle AChRs, which mediate excitatory transmission at the neuromuscular junction, the functions of neuronal AChRs remain largely unknown. The limited examples of excitatory nicotinic transmission documented in the nervous system has prompted the hypothesis that the receptors instead serve other functions. A prime candidate is the regulation of transmitter release if AChRs are located at presynaptic sites (for review, see Role and Berg, 1996; Wonnacott, 1997).

Early evidence for presynaptic AChRs came from anatomical studies of AChR distribution in situ (Clarke and Pert, 1985; Clarke et al., 1986; Henley et al., 1986; Swanson et al., 1987) and from biochemical studies examining nicotine effects on transmitter release from synaptosomes and slice preparations (Rapier et al., 1990; Grady et al., 1992; El-Bizri and Clarke, 1994; Yu and Wecker, 1994). Electrophysiological studies provided strong evi-

\footnotetext{
Received Jan. 22, 1997; revised April 29, 1997; accepted May 22, 1997.

This work was supported by National Institutes of Health Grants NS 12601 and 35469 and by the Muscular Dystrophy Association and the Council for Tobacco Research (4191). J.S.C. is a National Research Service Award Fellow; J.P. is a Fellow of the Swiss National Science Foundation and the Deutsche Forschungsgemeinschaft. We thank Dr. Jon Lindstrom (University of Pennsylvania, Philadelphia) for generously supplying monoclonal antibodies.

Correspondence should be addressed to Dr. Darwin K. Berg, Department of Biology, 0357, University of California, San Diego, 9500 Gilman Drive, La Jolla, CA 92093-0357.

Dr. Paysan's present address: Eberhard-Karls-Universitat Tubingen, Institut fur Physiologie Abt. II, D-72076, Tubingen, Germany.

Copyright (C) 1997 Society for Neuroscience $0270-6474 / 97 / 175798-09 \$ 05.00 / 0$
}

dence for presynaptic AChRs by showing that nicotine applied to slice preparations increased spontaneous postsynaptic events in a manner consistent with increased transmitter release from nerve terminals (Lena et al., 1993; McMahon et al., 1994 a,b; Bordey et al., 1996). More recently, activation of presynaptic AChRs has been shown to produce long-lasting calcium-dependent increases in transmitter release and to involve the AChR $\beta 2$ gene product (Lena and Changeux, 1997).

Receptors containing $\alpha 7$ subunits are one of the most abundant AChR species in the nervous system (Schoepfer et al., 1990; Gotti et al., 1994; Gerzanich et al., 1995); they avidly bind $\alpha$-bungarotoxin $(\alpha \mathrm{Bgt})$ and display a high relative permeability for calcium (Bertrand et al., 1993; Seguela et al., 1993). Pharmacological analysis of synaptic activity in cell culture has provided the first evidence that such receptors can modulate transmitter release from presynaptic sites (McGehee et al., 1995; Alkondon et al., 1996; Gray et al., 1996). Calcium imaging of presynaptic structures both in cell culture (McGehee et al., 1995) and in hippocampal slices (Gray et al., 1996) has permitted a direct visualization of the effects such receptors produce. Recently, patch-clamp recording from growing neurites in spinal cord cultures has revealed nicotine-induced currents that can be blocked by $\alpha \mathrm{Bgt}$ as expected for AChRs with $\alpha 7$ subunits (Fu and Liu, 1997).

Accessory motor neurons in the chick midbrain provide a possible system for a direct demonstration of nicotine-induced presynaptic currents in situ. The neurons extend axons to the ciliary ganglion where they terminate in large calyces on ciliary cells (De Lorenzo, 1960; Hess, 1965). The calyces are sufficiently large to permit patch-clamp recording of currents directly from 
the synaptic terminal (Stanley and Goping, 1991; Yawo and Momiyama, 1993). Excitatory chemical transmission at the synapse is nicotinic cholinergic, being mediated on the postsynaptic cell by two classes of AChRs. One class is located partly in the postsynaptic membrane, contains several gene products $(\alpha 3, \beta 4$, $\alpha 5, \pm \beta 2$ ), and contributes to synaptic transmission (Vernallis et al., 1993; Conroy and Berg, 1995). The other class is more abundant, contains the $\alpha 7$ gene product, and is concentrated in perisynaptic clusters (Vernallis et al., 1993; Wilson Horch and Sargent, 1995). Recent experiments demonstrate that the latter class actually contributes much of the postsynaptic current in the neurons, despite the perisynaptic location (Zhang et al., 1996). Presynaptic AChRs have not been described previously in the chick ciliary ganglion.

\section{MATERIALS AND METHODS}

Tissue preparation. Ciliary ganglia were dissected with nerve roots attached from embryonic day 14 (E14) chicks. The dissected ganglia were incubated with collagenase $(8 \mathrm{mg} / \mathrm{ml}$, type A, Boehringer Mannheim, Indianapolis, IN) in divalent-free buffer containing (in $\mathrm{mM}$ ): $140 \mathrm{NaCl}, 4$ $\mathrm{KCl}, 10$ glucose, and $10 \mathrm{HEPES}, \mathrm{pH} 7.4$, for $\sim 1 \mathrm{~min}$, and then transferred to a second solution containing protease $(6 \mathrm{mg} / \mathrm{ml}$, type XIV, Sigma, St. Louis, MO) in divalent-free buffer for an additional minute. The enzyme-treated ganglia were then mechanically stripped of debris and loosened tissue in divalent-free buffer and transferred to a recording chamber superfused with recording medium containing (in mM): 120 $\mathrm{NaCl}, 4 \mathrm{KCl}, 10$ glucose, $2 \mathrm{CaCl}_{2}, 1 \mathrm{MgSO}_{4}, 1 \mathrm{NaH}_{2} \mathrm{PO}_{4}$, and 25 $\mathrm{NaHCO}_{3}, \mathrm{pH} 7.4$, and gassed with $95 \% \mathrm{O}_{2} / 5 \% \mathrm{CO}_{2}$ at $\sim 3 \mathrm{ml} / \mathrm{min}$ starting $30 \mathrm{~min}$ before recording.

Whole-cell patch-clamp recording. Patch-clamp recording from neurons in intact ganglia was performed as described previously (Yawo and Chuhma, 1994; Zhang et al., 1996). Patch pipettes (2-3 M $\Omega$ ) were pulled from borosilicate glass $(1.5 \mathrm{~mm}$ outer diameter, Drummond Scientific, Broomall, PA). Intracellular solution contained (in mM): $140 \mathrm{CsCl}, 2$ EGTA, 10 glucose, $3 \%$ (w/v) Lucifer yellow-CH, and 10 HEPES, $\mathrm{pH} 7.2$ with $\mathrm{CsOH}$. Series resistances averaged $8.7 \pm 0.5 \mathrm{M} \Omega$ (mean \pm SEM; $n=37)$ for cell bodies and $17.2 \pm 1.1 \mathrm{M} \Omega(n=27)$ for calyces. These values are similar to those reported previously (Yawo and Momiyama, 1993). Series resistance compensation ranged from 20 to $80 \%$. Recordings were discarded if the series resistance exceeded $28 \mathrm{M} \Omega$, the baseline was unstable, or regenerative currents indicative of action potentials occurred spontaneously. Both calyces and cell bodies were routinely clamped at $-60 \mathrm{mV}$.

Visualization of calyces was often facilitated by use of infrareddifferential interference contrast imaging that included a Dage-MTI VE-1000 system with an HR-1000 A/B multiscan high-resolution monitor and a 770/220 bandpass filter. For most cell bodies and some calyces, only differential interference contrast with a blue filter was used to select targets for patch-clamp recording. The preparation was viewed with an upright microscope (Zeiss Axioskop, Oberkochen, Germany) using a $40 \times$ water-immersion objective. Patch-clamped structures were routinely filled with Lucifer yellow- $\mathrm{CH}$ from the recording pipette and were monitored visually throughout the recording session. All recordings attributed to calyces were from structures confirmed by dye-fill in this manner to have the morphology of a calyx.

Currents were amplified with an Axopatch $1 \mathrm{C}$ amplifier (Axon Instruments, Foster City, CA). Data were filtered at $1-10 \mathrm{kHz}(-3 \mathrm{~dB}$, eight-pole Bessel filter, frequency device). Data were stored on videotape (Sony VCR, VR-10B A/D converter, Instrutech, Mineola, NY) and digitized later at $5 \mathrm{kHz}$ (pClamp DigiData 1200, Axon Instruments). Statistical analysis was performed with Microsoft Excel or Sigma Plot. All recordings were made from cell bodies or calyces on the surface of the ganglion.

Dye-filling and confocal microscopy. Calyces or cell bodies in E14 ciliary ganglia were filled selectively with biocytin or neurobiotin by placing crystals of the dye on either the pre- or the postganglionic nerve root, respectively, for several minutes. Ganglia were then rinsed, incubated for up to $1 \mathrm{hr}$ in extracellular recording solution at room temperature, and fixed with $4 \%$ paraformaldehyde in $0.15 \mathrm{~m}$ sodium phosphate, $\mathrm{pH}$ 7.4. Ganglia were permeabilized with $0.2 \%(\mathrm{v} / \mathrm{v})$ Triton X-100 in 0.14 $\mathrm{M} \mathrm{NaCl}$ with $0.01 \mathrm{M}$ sodium phosphate, $\mathrm{pH} 7.4$, and were stained with FITC-coupled streptavidin (1-1000 dilution from stock, Jackson Labo- ratories, Bar Harbor, ME). Staining was analyzed with a Noran Odyssey confocal laser scanning microscope. Alternatively, Lucifer yellow-filled structures were visualized by filling individual cell bodies or calyces with dye from a patch pipette and viewing directly.

Solid-phase immunoprecipitation assays. Solid-phase immunoprecipitation assays were performed as described previously (Conroy and Berg, 1995). Briefly, segments of the oculomotor nerve $(2-6 \mathrm{~mm})$ were dissected from E14-E15 chick embryos (one segment per nerve) and then combined (10-20 segments) to be homogenized in buffer containing Triton X-100 to solubilize membrane components. The supernatant fraction was collected by centrifugation, and aliquots were incubated in microtiter wells precoated with antibodies. The anti- $\alpha 7$ monoclonal antibodies (mAbs) 318 and 319 were used to immunotether AChRs containing the $\alpha 7$ gene product, and $\left[{ }^{125} \mathrm{I}\right] \alpha \mathrm{Bgt}$ was used to quantify the receptors bound. The anti- $\alpha 3 \mathrm{mAb}$ A3-1 and the anti- $\beta 4 \mathrm{mAb}$ B4- 1 were combined to immunotether AChRs containing the $\alpha 3$ or $\beta 4$ gene products, respectively, and $\left[{ }^{125} \mathrm{I}\right] \mathrm{mAb} 35$ was used in this case to quantify receptors bound. The specificities of the antibodies have been documented previously (see Vernallis et al., 1993, their references).

Materials. White Leghorn chick embryos were obtained locally and maintained at $37^{\circ} \mathrm{C}$ in a humidified incubator. mAbs 318 and 319 were generously provided by Dr. Jon Lindstrom (University of Pennsylvania, Philadelphia). $\alpha$ Bgt was obtained from Biotoxins (St. Cloud, FL); neurobiotin (MW 367) and biocytin (MW 372) from Molecular Probes (Eugene, OR); FITC-streptavidin from Jackson Laboratories; Lucifer yellow- $\mathrm{CH}$ from Aldrich (Milwaukee, WI); and D-tubocurarine from RBI (Natick, MA). All other drugs were obtained from Sigma. For electrophysiological experiments, drugs were dissolved in extracellular recording medium and delivered by gravity feed from a series of reservoirs.

\section{RESULTS}

\section{Nicotine-induced currents in presynaptic calyces}

The whole-cell configuration of the patch-clamp technique was used to record nicotine-induced currents from presynaptic calyces in E14 ciliary ganglia. The ganglia were freshly dissected with nerve roots attached, and nicotine was applied by superfusion through the bath. Successful recordings were obtained from 31 calyces. Approximately two thirds of those exposed to $100 \mu \mathrm{M}$ nicotine (14 of 20 calyces) displayed both a sustained slow inward current and a series of stereotypical regenerative currents (Fig. $1 A$, top trace). The regenerative currents were produced by unclamped action potentials (see below) and will be referred to here as current spikes. In the remaining calyces exposed to $100 \mu \mathrm{M}$ nicotine (7 of 20), no slow inward current was detectable over background, but the current spikes were still observed. The inset in Figure $1 A$ shows a representative current spike on an expanded time scale. Slow inward currents were never observed in response to superfusion with vehicle. Only in rare instances were current spikes found in the absence of nicotine, possibly because of nerve damage; such cases were discarded.

The nicotine-induced slow inward currents are consistent with the presence of presynaptic AChRs. The amplitude of the currents averaged $-2.0 \pm 0.5 \mathrm{pA} / \mathrm{pF}( \pm \mathrm{SEM} ; n=14)$, but both here and below, such values should be considered only best estimates because of limitations in the space clamp that introduce inaccuracies in the determination of both the measured current and the capacitance. The presence of current spikes indicates that the patch pipette was insufficient to maintain voltage clamp throughout the terminal, presumably because of the extended morphology of the calyx and attached axon. Limitations in the space clamp achieved with patch pipettes in this preparation have been noted previously (Stanley and Goping, 1991; Yawo and Momiyama, 1993). In the present studies, the limited space clamp proved to be a strength because it permitted a direct demonstration of the ability of AChRs to excite the terminal and influence transmitter release. The fact that nicotine triggered current spikes in some cases without an obvious slow inward current suggests 
A Nicotine $(100 \mu \mathbf{M})$

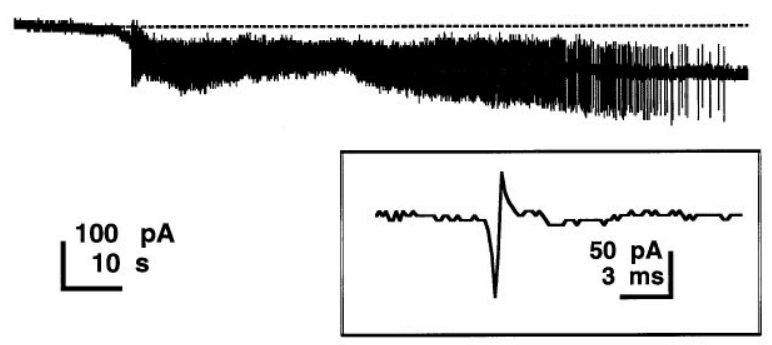

Nicotine $(1 \mu \mathrm{M})$
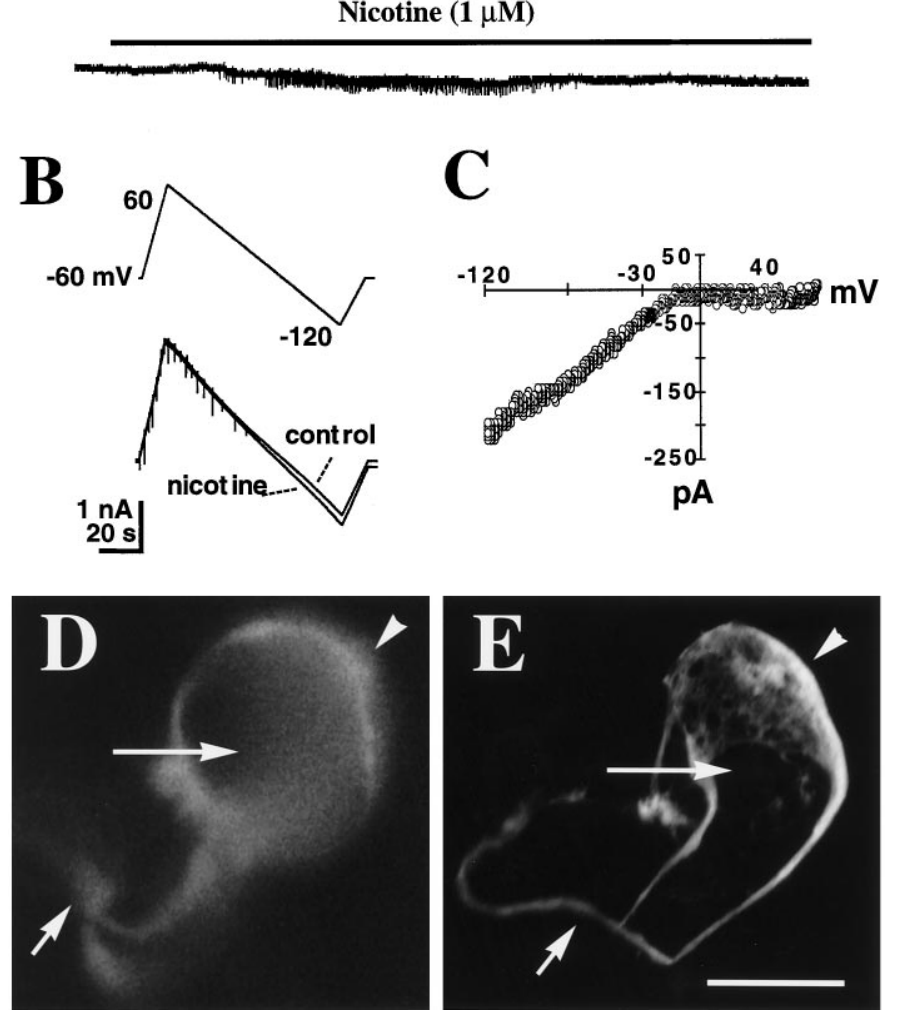

Figure 1. Nicotine-evoked currents in presynaptic calyces. A, Patchclamp recording from a calyx showing nicotine-evoked inward current and overlying current spikes caused by action potentials that escaped space clamp. Top trace, Nicotine $(100 \mu \mathrm{M})$ was bath-applied to an E14 chick ciliary ganglion by gravity feed (thick horizontal bar). A slow inward current was induced several seconds after the initiation of agonist perfusion. A train of regenerative current spikes attributable to action potentials followed, visible because the complex geometry of the calyx and presynaptic axon prevents a complete space clamp. The inset shows a single current spike on an expanded time scale. Bottom trace, Response to $1 \mu \mathrm{M}$ nicotine evokes current spikes and a barely detectable inward current. $B$, Currents induced by voltage ramps in the presence and absence of nicotine. Voltage ramps were applied to the calyx (top trace; -60 up to $60 \mathrm{mV}$, then down at $-120 \mathrm{mV} / \mathrm{sec}$ to -120 $\mathrm{mV}$, and back to $-60 \mathrm{mV}$ ) before (bottom trace, control) and after (bottom trace, nicotine) superfusion with $100 \mu \mathrm{M}$ nicotine. $C$, Currentvoltage plot for the nicotine-induced response calculated as the difference between the control and nicotine traces from $B$. Similar results were obtained with two other calyces. $D$, A presynaptic calyx filled with Lucifer yellow viewed with fluorescence microscopy using a Zeiss Axioskop immediately after recording (same calyx that produced the top trace in $A$ ). The presynaptic axon appears bifurcated immediately before the calyx; the dye-fill reveals the calyx enveloping the cell. The interior of the cell remains unlabeled, indicating the absence of an electrical synapse between calyx and cell body. $E$, The same calyx from $A$ viewed with confocal microscopy after compressing the ganglion between slide and coverslip. The manipulation that the site of receptor activation can be some distance from the patch pipette. Usually little desensitization of the response was apparent over the duration of nicotine application (Fig. $1 \mathrm{~A}$, top trace).

When nicotine was bath-applied at 10-20 $\mu \mathrm{M}$, it evoked a detectable slow inward current in three of four calyces tested and triggered current spikes in all four. The mean amplitude of the slow inward current was $-1.3 \pm 0.4 \mathrm{pA} / \mathrm{pF}(n=3)$. At $1 \mu \mathrm{M}$, nicotine failed to evoke detectable slow inward currents but did in one of three calyces trigger a train of current spikes (Fig. 1A, bottom trace). The amplitudes of the nicotine-induced current spikes appeared to vary considerably among calyces, presumably depending on the location and reach of the space clamp. A more extensive space clamp, for example, would force regenerative currents to travel farther by passive propagation to reach the patch pipette and, as a result, would undergo more attenuation before being recorded.

The current-voltage relationship of the nicotine-induced response was examined to determine whether it reversed near $0 \mathrm{mV}$ as expected for currents flowing through AChRs. The alternative possibility was that $\mathrm{K}^{+}$efflux from the postsynaptic cell drove inward currents through $\mathrm{K}^{+}$channels, which, under the ionic gradients being used $\left(\mathrm{Cs}^{+}\right.$inside $/ \mathrm{K}^{+}$outside), would reverse at highly positive potentials. A ramp depolarization was applied to the calyx via the recording pipette as described previously (Sun and Stanley, 1996) in the presence and absence of nicotine (Fig. $1 B)$. The current-voltage relationship for the nicotine-induced response, calculated as the difference between the two ramp curves, reversed near $0 \mathrm{mV}$ and showed inward rectification (Fig. $1 C$ ). The results exclude currents through $\mathrm{K}^{+}$channels as contributing significantly to the nicotine-induced responses measured in the presynaptic terminals.

Confirmation that the structures being patch-clamped were actually presynaptic calyces was routinely obtained by filling the structures with Lucifer yellow- $\mathrm{CH}$ from the patch pipette while the recordings were being made. The dye-filled structure could be visualized directly during the course of the experiment (Fig. 1D). The same calyx could be viewed subsequently with confocal microscopy at the end of the experiment (Fig. 1E), although the labeled calyx was sometimes damaged by removal of the patch pipette and compression of the ganglion between slide and coverslip. The confocal image clearly indicated the absence of dye transfer to the cell body, suggesting that no electrical synapse was present. The image also indicated what may be a bifurcation in the preganglionic axon before terminating in the calyx; such bif urcated preganglionic processes were relatively common. The calyx shown in $D$ and $E$ is the same as that providing the top current trace in Figure $1 A$.

\section{Toxin blockade of presynaptic responses}

The nicotine-induced responses in calyces were dissected pharmacologically. The sodium channel blocker tetrodotoxin (TTX), at $1 \mu \mathrm{M}$, completely eliminated the nicotine-induced current spikes when exposure was initiated several minutes before delivery of nicotine (eight of eight calyces). TTX did not have a significant effect on the amplitude of the nicotine-induced slow

$\leftarrow$

partially disrupted the calyx, but its contours still can be distinguished along with what may be the bifurcated axon. The long arrows indicate cell body; arrowheads, calyx; short arrows, axon. Scale bar (shown in E), $20 \mu \mathrm{m}$. 
A

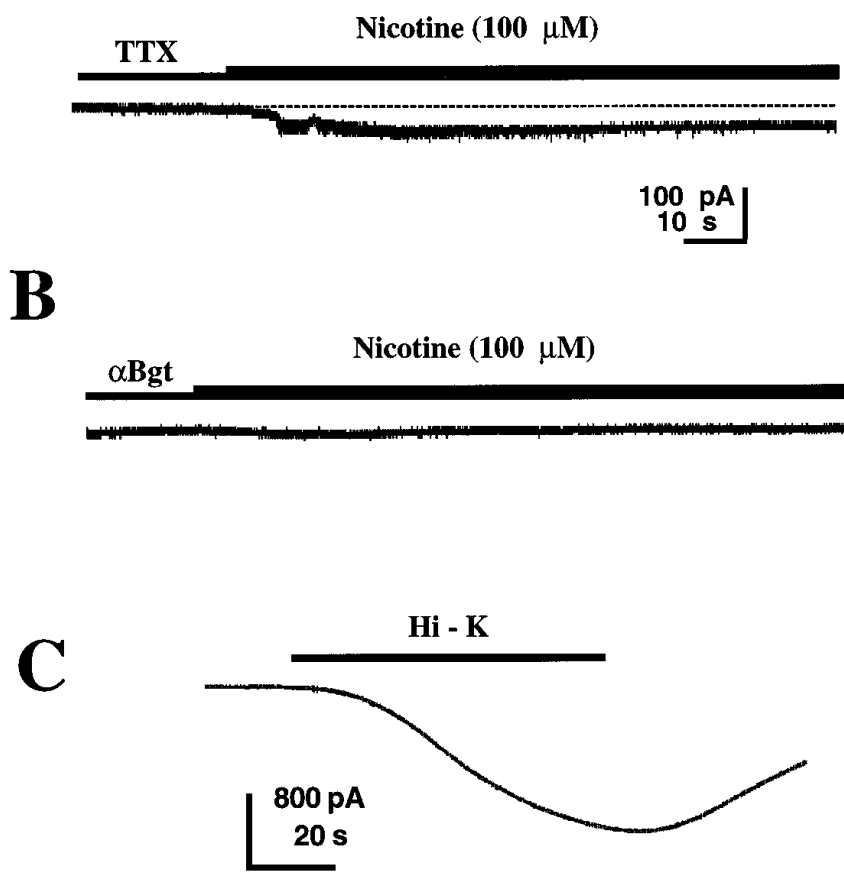

Figure 2. Toxin blockade of nicotine-induced presynaptic currents and kinetics of the superfusion system. $A$, Resistance of presynaptic nicotineinduced current to TTX. TTX was bath-applied at $1 \mu \mathrm{M}$ several minutes before delivery of nicotine. The nicotine-induced slow inward current remained even though the TTX treatment eliminated the overlying current spikes. $B$, Blockade of presynaptic nicotine-induced current by $\alpha \mathrm{Bgt}$. $\alpha$ Bgt was bath-applied at $60 \mathrm{~nm}$ for $10 \mathrm{~min}$ before perfusion with nicotine. No currents were induced by the agonist. Solid bars depict drug application. Traces in $A$ and $B$ are from different cells. $C$, Time course of solution exchange achieved with the superfusion system. A patch pipette was filled with normal intracellular recording medium and placed at the surface of a ganglion in the recording chamber. Superfusion was initiated with a solution containing an elevated concentration of potassium. As the high potassium solution reached the patch pipette, it induced a junction potential at the tip of the electrode, leading to a current that was recorded and used to monitor the solution exchange. The solid bar indicates the time at which the high potassium solution $(\mathrm{Hi}-\mathrm{K})$ first entered the bath. At least $60 \mathrm{sec}$ were required for a substantial solution exchange to occur at the surface of the ganglion where the patch pipette was positioned.

inward current, yielding an average value of $-2.2 \pm 0.7 \mathrm{pA} / \mathrm{pF}$ (six of six calyces) (Fig. $2 A$ ). $\alpha$ Bgt, which completely blocks the response of AChRs containing $\alpha 7$ subunits (Couturier et al., 1990; Z hang et al., 1994), blocked completely both the nicotineinduced slow inward current and the nicotine-induced current spikes. Blockade by $\alpha$ Bgt was complete when the toxin was applied at $60 \mathrm{nM} 10 \mathrm{~min}$ before application of $100 \mu \mathrm{M}$ nicotine (four of four calyces) (Fig. 2B).

The lack of desensitization for the nicotine-induced currents and the high concentration of nicotine required for a sizable response were unexpected in view of past results obtained with $\alpha$ Bgt-sensitive responses from ciliary ganglion neurons (Z hang et al., 1994, 1996). We considered the possibility that inefficiencies in the superfusion system accounted for the differences. A micropipette filled with normal intracellular medium was placed at the surface of the ganglion, whereas the recording chamber was superfused first with normal extracellular solution (to establish the baseline) and then with a solution containing a high concentration of $\mathrm{K}^{+}$(normal extracellular solution with $\mathrm{KCl}$ increased to $90 \mathrm{~mm}$ and $\mathrm{NaCl}$ decreased to $35 \mathrm{~mm}$ ). The resulting change in junction potential at the tip of the pipette (Fig. $2 C$ ) provided an indication of how rapidly the superfusion exchanged solutions at the ganglion surface. By this criterion, the agonist concentration reaching the cells is seen to increase only very slowly and is likely even at maximum to have been substantially lower than the reservoir concentration. Because the rate of desensitization for $\alpha$ Bgt-AChRs on ciliary ganglion neurons declines with decreasing agonist concentration (Zhang et al., 1994), the slow perfusion almost certainly contributed to the apparent lack of desensitization seen in the presynaptic response. The results also caution against overinterpreting dose-response determinations for nicotine-induced currents based on nominal nicotine concentrations in the superfusion system.

\section{Nicotine-evoked responses in ganglionic cell bodies}

The fact that bath-applied nicotine at $100 \mu \mathrm{M}$ routinely induced current spikes indicative of action potentials in the presynaptic calyx suggested that the treatment should also elicit EPSCs in ganglionic cell bodies, because the presynaptic action potentials should trigger transmitter release from the terminals. EPSCs evoked in this manner might be superimposed on nicotineinduced inward currents in ganglionic cell bodies because AChRs are present on the cells. As noted above, one class of AChRs on ciliary ganglion neurons contains the $\alpha 7$ gene product, generates a rapidly decaying response, and is blocked by $\alpha \mathrm{Bgt}$, whereas another class contains different gene products, generates a slowly decaying response, and is not blocked by $\alpha \mathrm{Bgt}$ (Vernallis et al., 1993; Zhang et al., 1994).

Whole-cell patch-clamp recording from cell bodies in the ganglion showed that bath application of $100 \mu \mathrm{M}$ nicotine elicited a slow, bimodal inward current in 13 of 14 cells (mean peak amplitude of $21.1 \pm 5.4 \mathrm{pA} / \mathrm{pF}$ ). Decay constants of $3.6 \pm 1.0 \mathrm{sec}$ (mean \pm SEM; $n=8$ cells) and $29.0 \pm 4.2 \mathrm{sec}(n=11)$ were calculated for the two components of the bimodal response in those cases in which they were sufficiently distinct in time to permit resolution. Often the currents were overlaid with EPSCs ( 8 of 14 cells) (Fig. $3 A$, top trace). The inset shows an EPSC on an expanded time scale (taken from the top trace in Fig. $3 A$ ). Sometimes the EPSCs appeared before the onset of the inward current, suggesting that the current did not initiate the EPSCs. The exposure to nicotine also consistently increased the noise of the recording. At $1 \mu \mathrm{M}$, nicotine did not evoke a detectable inward current and yet could still elicit EPSCs (three of six cells) (Fig. $3 A$, bottom trace). The response latencies were prolonged at the lower agonist concentration. The results are consistent with nicotine triggering action potentials in the presynaptic terminal, which elicit EPSCs in the postsynaptic cell; the bimodal inward current, in contrast, is likely to be caused by direct activation of AChRs on the cell body.

Because action potentials evoked by nicotine in the calyx are blocked by TTX, treatment of the ganglion with the compound should prevent bath-applied nicotine from eliciting EPSCs in postsynaptic cell bodies. Indeed, preincubation of ganglia for several minutes in $1 \mu \mathrm{M}$ TTX eliminated completely the EPSCs (five of five cells) (Fig. 3B) while having no significant effect on the inward currents. A mean peak value of $14.4 \pm 2.0 \mathrm{pA} / \mathrm{pF}(n=$ 4 cells) was obtained for nicotine-induced slow inward currents in TTX. The EPSCs were eliminated completely by bath application of $60 \mathrm{nM} \alpha \mathrm{Bgt}$ for $15 \mathrm{~min}$ (four of four cells) (Fig. 3C), consistent with the ability of $\alpha \mathrm{Bgt}$ to block all of the presynaptic nicotinic response. The remaining $\alpha$ Bgt-resistant slow component of the 


\begin{abstract}
Figure 3. Responses elicited in ciliary ganglion cell bodies by bath-applied nicotine. $A$, Top trace, Nicotine-evoked inward current and EPSCs in a ganglionic cell body. Bath-applied nicotine $(100 \mu \mathrm{M})$ elicited a slow, bimodal inward current that was overlaid with EPSCs and accompanied by an increase in noise. The inset shows an EPSC from the same cell on an expanded time scale. Bottom trace, Bath-applied nicotine $(1 \mu \mathrm{M})$ elicited no detectable inward current, but EPSCs were still apparent. $B$, TTX blockade of the EPSCs. Bath application of nicotine after incubation with $1 \mu \mathrm{M}$ TTX still produced an inward current in cell bodies, but the EPSCs were no longer apparent. $C$, $\alpha$ Bgt blockade of the fast component of the bimodal response and the EPSCs induced by nicotine. $\alpha$ Bgt at $60 \mathrm{~nm}$ was applied $15 \mathrm{~min}$ before perfusion with nicotine. Only the slow component of the nicotine-induced inward current was observed. Both the fast inward current and the EPSCs were absent. $D$, D-Tubocurarine blocks all nicotineinduced responses in the cell body. Application of $60 \mu \mathrm{M}$ D-tubocurarine for 6 min before the nicotine blocked both components of the bimodal inward current, confirming that both were generated by AChRs. The solid bars depict drug application. The traces in $A-D$ were obtained from four different cells. $E$, Dye-filling of the cell body with Lucifer yellow from the patch pipette. The cell body was filled with Lucifer yellow during the recording with no apparent transfer to the associated calyx. Scale bar (shown in $E$ ), $10 \mu \mathrm{m}$.
\end{abstract}

A
B
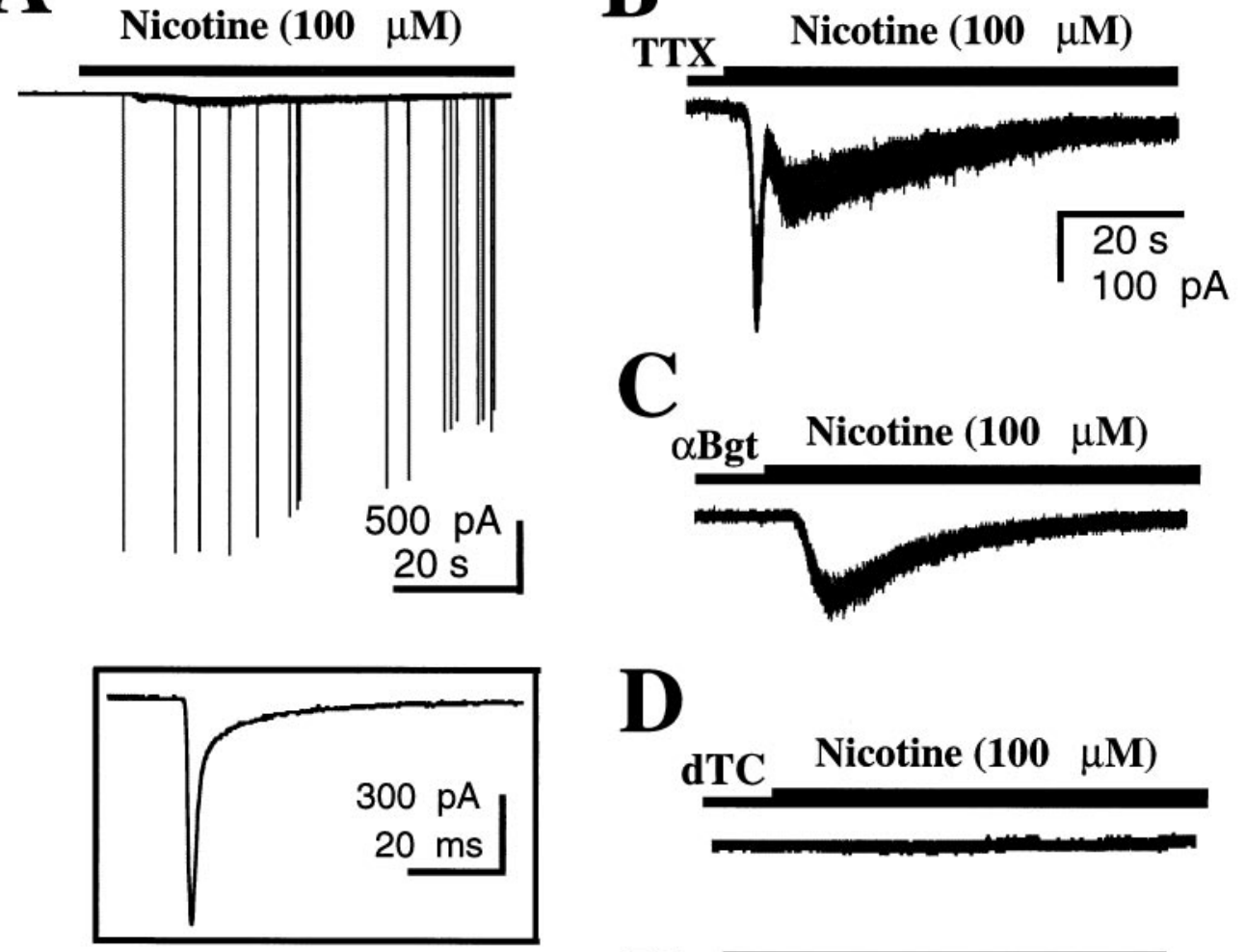

D

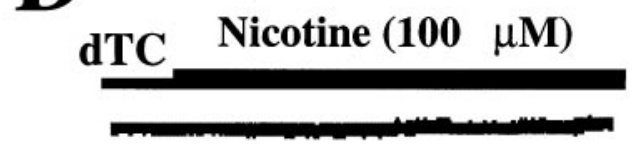

$\mathbf{E}$
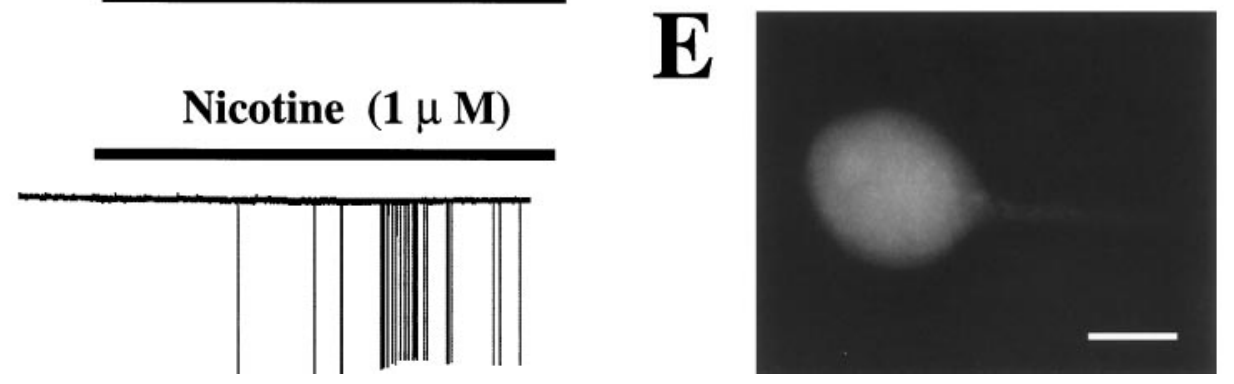

bimodal response had a mean peak value of $8.3 \pm 0.9 \mathrm{pA} / \mathrm{pF}(n=$ 4 cells). Both components of the nicotine-induced bimodal response, along with the nicotine-induced EPSCs, were blocked completely by application of $60 \mu \mathrm{M}$ D-tubocurarine for 3-6 min before perfusion with $100 \mu \mathrm{M}$ nicotine (four of four cells) (Fig. $3 D$ ). Dye-filling from the patch pipette during the recording periods was used to visualize the patch-clamped structures; the dye-fills consistently revealed cell bodies in these cases. An example is shown in Figure $3 E$.

\section{Lack of dye-coupling between ganglionic neurons and presynaptic calyces}

Because electrical synapses form between preganglionic nerve terminals and ciliary cells late in embryogenesis (Martin and Pilar, 1963), it became important to consider whether current originating in the cell body and passing through electrical synapses might contribute significantly to nicotine-induced currents observed in calyces. Previous electrophysiological analysis indicated that electrical synapses between presynaptic calyces and postsynaptic ciliary ganglion neurons are relatively rare at E14, the developmental stage examined here (Yawo and Momiyama, 1993; Zhang et al., 1996). Moreover, the Lucifer yellow dye-fills of individual calyces or cell bodies from the patch pipette in the present experiments never revealed dye transfer from the calyx to the cell body or vice versa. These results are in agreement with past studies showing the absence of dye transfer between pre- and postsynaptic elements in the ganglion at similar developmental stages using Lucifer yellow loaded via either nerve roots or patch pipette (Stanley, 1989; Stanley and Goping, 1991).

Additional experiments to assess the incidence of electrical synapses in E14 ganglia made use of neurobiotin and biocytin, two dyes known to pass readily through gap junctions (Vaney, 1991; Robinson et al., 1993). Dye crystals were applied to the preganglionic nerve root for labeling of calyces en mass or to the postganglionic nerve root for labeling of cell bodies en mass. After uptake and transport of the dye, the ganglia were stained and examined with confocal laser fluorescence microscopy. Calyces labeled by dye transported along the preganglionic nerve root usually appeared as ring-like structures surrounding much of the cell perimeter when the plane of focus transected the cell (Fig. $4 A$ ). Sometimes the labeled preganglionic axon could be distinguished in the same plane of focus. When the plane of focus was adjusted to view the upper or lower surface of the cell, the labeling pattern usually revealed an extended calciform structure, often resembling a mat of fine processes (Fig. $4 B$ ). In some cases, the labeled terminals appeared as multiple discrete ovoid structures on the cell body (Fig. $4 C$ ). The complex geometry of the 

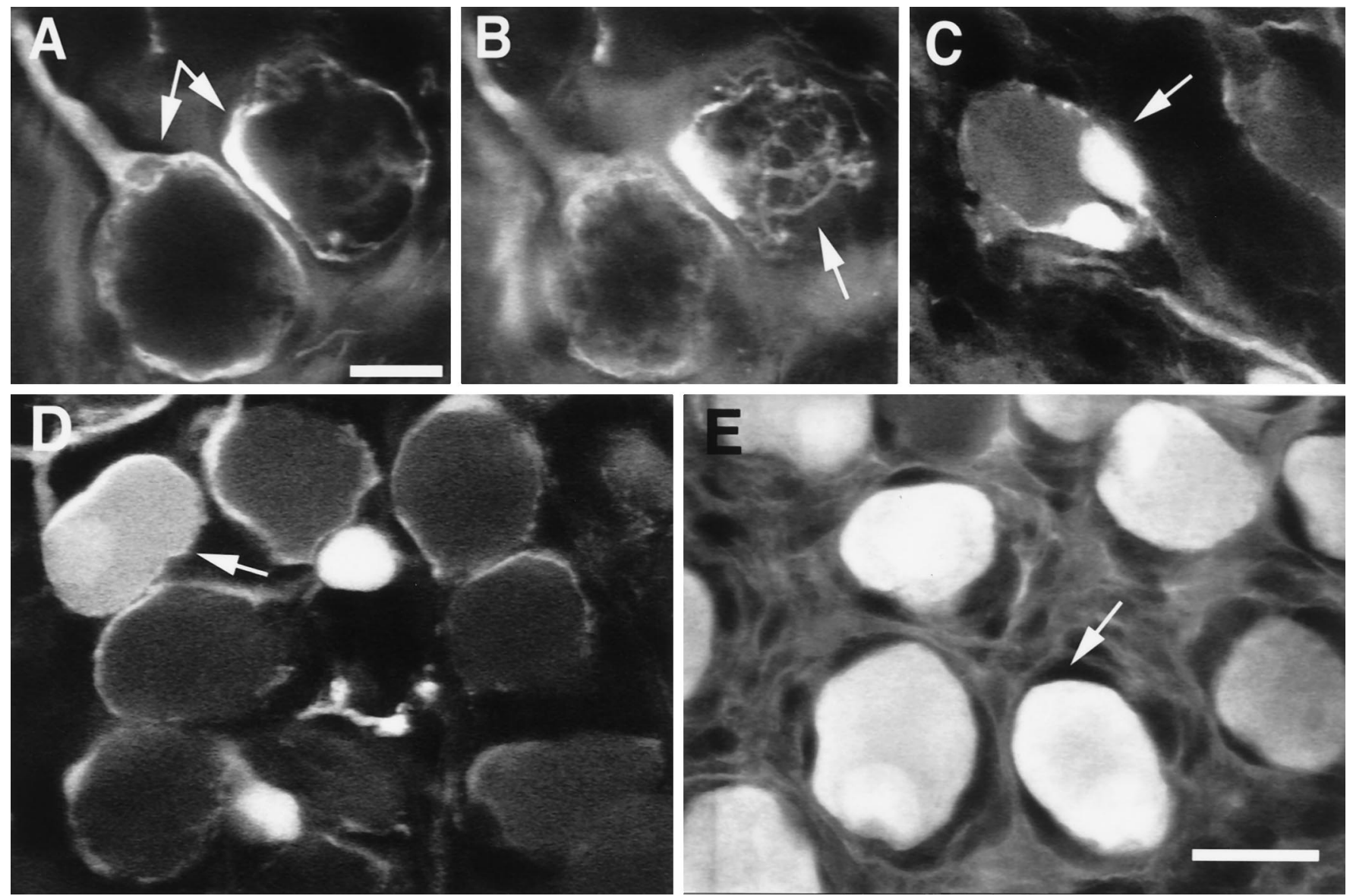

Figure 4. Absence of dye transfer between presynaptic calyces and postsynaptic cell bodies in E14 ciliary ganglia. E14 chick ciliary ganglia were dissected with nerve roots attached and labeled by placing neurobiotin crystals either on the preganglionic nerve root to label calyces or on the postganglionic root to label ganglion cell bodies. Several minutes later, the ganglia were rinsed, incubated for $1 \mathrm{hr}$, fixed, permeabilized, labeled with FITC-streptavidin, and viewed with confocal fluorescence microscopy. $A$, Optical section through a ciliary neuron showing the surrounding stained calyx (long arrow) in cross section with preganglionic axon attached, and a neighboring cell with calyx visible (short arrow) but no axon in the plane of focus. $B$, Optical section near the top of a ciliary neuron from $A$ showing the stained cap-like mesh of fibers (arrow) comprising the calyx. $C$, Stained presynaptic terminal consisting of several ovoid structures (arrow) on the ganglionic cell body. $D$, A number of stained calyces, including the one case seen of dye transfer having occurred from a filled calyx to the underlying cell body (arrow). The smaller round labeled structure in the center is representative of large swellings/varicosities sometimes found along the preganglionic axon. $E$, A number of cell bodies labeled by retrograde filling with neurobiotin through the postganglionic nerve root. In some cases, the labeled postganglionic axon can be distinguished in the plane of focus. Unlabeled calyces appear as dark spaces (example indicated by arrow) encapsulating the cell bodies and being demarcated by extracellular material. Three-dimensional analysis failed to reveal dye transfer to presynaptic calyces, indicating that it must be a rare event at E14. Similar results were obtained with biocytin. Scale bars: $A-C, 10 \mu \mathrm{m} ; D, E, 20 \mu \mathrm{m}$.

calyces offers a clear explanation as to why a patch pipette would have difficulty in maintaining a space clamp throughout the structure and how nicotine-induced currents at sites far from the pipette could induce action potentials in the presynaptic terminal.

Among hundreds of cases examined with neurobiotin or biocytin staining, only two examples were found in which a transfer of dye occurred from a calyx to a cell body. One is shown in Figure $4 D$, along with numerous examples of labeled calyces without dye transfer to the cell body. The calyx dye-fills suggest a low incidence of electrical synapses having formed between presynaptic terminals and ciliary neuron cell bodies by E14. A similar conclusion emerged when cell bodies were labeled by retrograde transport of dye along the postganglionic nerve root. Labeled cell bodies could be readily distinguished, but the surrounding space occupied by the calyx and demarcated by extracellular matrix and passing axons remained devoid of dye (Fig. 4E). Threedimensional reconstruction of optical sections confirmed this interpretation and indicated additionally that a single labeled axon was associated with each labeled cell. Had dye transferred to the presynaptic calyx, the preganglionic axon would have contained label as well and would have given the appearance of two axons (one preganglionic and one postganglionic) being associated with the same cell body. In conclusion, the nicotine-induced responses recorded in calyces cannot be attributed to AChRs on the cell body generating current that is passed through electrical synapses.

\section{Immunological detection of AChRs in the preganglionic nerve root}

Presynaptic AChRs must be synthesized in the cell body, transported along the axon, and deposited at the axon terminal. If they are transported in sufficient number, it should be possible to demonstrate their presence in the nerve. To address this, we dissected 2-6 mm segments of the oculomotor nerve immediately proximal to the branch supplying innervation to the ciliary ganglion. The segments were clearly distinct from the ganglion and should have contained no neuronal cell bodies. Nerve extracts were prepared by homogenizing pooled segments in detergent 


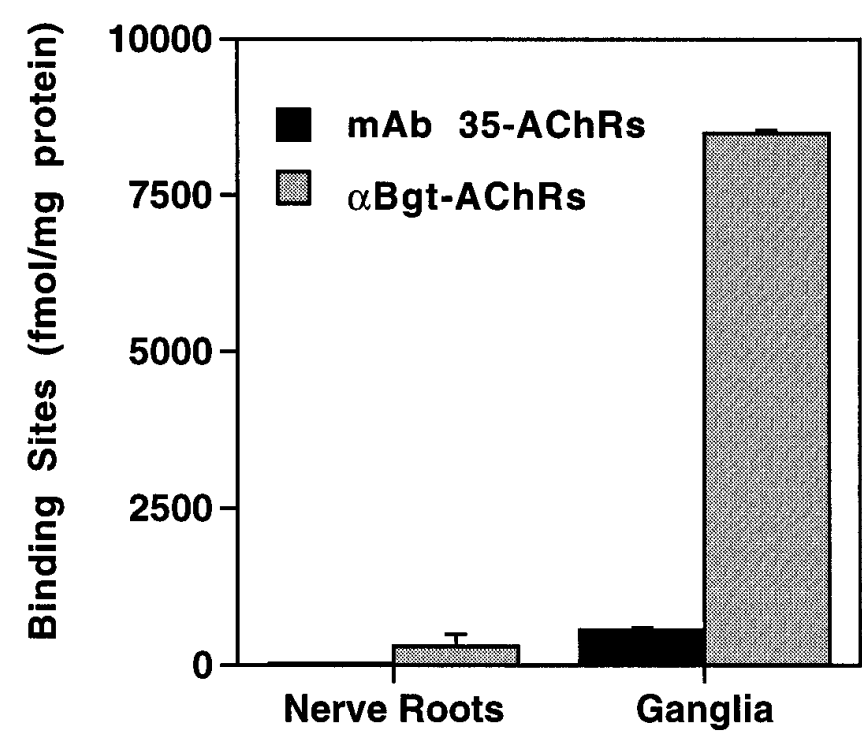

Figure 5. Immunochemical detection of AChRs containing the $\alpha 7$ gene product and binding $\alpha \mathrm{Bgt}$ in the preganglionic nerve. Segments of the oculomotor nerve $(2-6 \mathrm{~mm})$ immediately before the ciliary ganglion were dissected from E14-E15 chick embryos, pooled, and homogenized in buffer containing Triton X-100 to solubilize membrane components. Aliquots were analyzed in solid-phase immunoprecipitation assays performed in microtiter wells. The anti- $\alpha 7$ mAbs 318 and 319 were combined to immunotether AChRs containing the $\alpha 7$ gene product, and bound receptors were quantified with $\left[{ }^{125} \mathrm{I}\right] \alpha \operatorname{Bgt}(\alpha \operatorname{Bgt}-A C h R s)$. The anti- $\alpha 3 \mathrm{mAb}$ A3-1 and the anti- $\beta 4 \mathrm{mAb}$ B4- 1 were combined to immunotether AChRs containing the $\alpha 3$ and/or $\beta 4$ gene products, and bound receptors were quantified with $\left[{ }^{125} \mathrm{I}\right] \mathrm{mAb} 35(m A b 35-A C h R s)$. For a positive control, assays were performed in parallel with extracts prepared from E17-E18 ciliary ganglia. Values represent the mean $\pm \mathrm{SEM}$ of four experiments. Each experiment revealed significant amounts of receptor containing the $\alpha 7$ gene product in nerve extracts, although values varied considerably among experiments. No receptors binding mAb 35 and containing either the $\alpha 3$ or the $\beta 4$ gene products could be detected in the nerve extracts. Ciliary ganglion extracts, in contrast, had large numbers of both kinds of receptors as shown previously.

buffer, and aliquots were examined with solid-phase immunoprecipitation assays using subunit-specific mAbs. mAbs 318 and 319 were combined to immunotether AChRs containing the $\alpha 7$ gene product in the assay, and the bound receptors were quantified with $\left[{ }^{125} \mathrm{I}\right] \alpha$ Bgt. mAbs A3-1 and B4-1 were combined to immunotether AChRs containing the $\alpha 3$ and $\beta 4$ gene products, and bound receptors were quantified in this case with $\left[{ }^{125} \mathrm{I}\right] \mathrm{mAb} 35$.

Extracts prepared from the oculomotor nerve segments contained no detectable receptors that bound mAb 35, but they did have significant numbers of AChRs containing the $\alpha 7$ gene product and binding $\alpha$ Bgt (Fig. 5). Extracts prepared from ciliary ganglia and used as a positive control contained substantial amounts of AChRs that have $\alpha 3$ and/or $\beta 4$ subunits and bind $\mathrm{mAb} 35$. In addition, they had very high levels of AChRs that contain $\alpha 7$ subunits and bind $\alpha$ Bgt as reported previously (Vernallis et al., 1993). If the $\alpha$ Bgt-binding AChRs containing $\alpha 7$ subunits present in the oculomotor nerve are destined for preganglionic terminals, the receptors could produce the nicotineevoked, $\alpha$ Bgt-sensitive nicotinic responses recorded from calyces.

\section{DISCUSSION}

The results reported here show directly that nicotine can induce membrane currents in presynaptic terminals in situ, demonstrating unambiguously the presence of functional presynaptic
AChRs. The presynaptic response was blocked completely by $\alpha \mathrm{Bgt}$ as expected for AChRs containing the $\alpha 7$ gene product, and receptors binding $\alpha \mathrm{Bgt}$ and containing $\alpha 7$ subunits were detected immunochemically in the efferent nerve containing the presynaptic axons. Because AChRs with $\alpha 7$ subunits have a high relative permeability to calcium (Bertrand et al., 1993; Seguela et al., 1993) and readily elevate intracellular calcium levels (Vijayaraghavan et al., 1992), they may be well suited to modulate synaptic transmission.

The nicotinic responses recorded from presynaptic calyces in the ciliary ganglion cannot be attributed to currents generated by receptors located on the postsynaptic cell body and passed through electrical synapses. Dye-filling experiments with Lucifer yellow (Stanley, 1989; Stanley and Goping, 1991) and those reported here with Lucifer yellow, neurobiotin, and biocytin indicate few instances of electrical synapses at the developmental stage used. Electrophysiological analysis suggests a somewhat higher incidence (Yawo and Momiyama, 1993; Zhang et al., 1996), but still insufficient to account for the presynaptic currents. Moreover, the persistence of nicotine-induced presynaptic currents in time and their complete blockade by $\alpha \mathrm{Bgt}$ are incompatible with currents originating from activation of AChRs on the postsynaptic cell; postsynaptic responses contain $\alpha$ Bgt-sensitive and -resistant components, and both desensitize.

The presynaptic nicotinic responses also cannot be attributed to inward currents through $\mathrm{K}^{+}$channels driven by $\mathrm{K}^{+}$efflux from the postsynaptic cell. Had this been the case, the current should have reversed at very positive potentials with the ionic gradients being used rather than at near $0 \mathrm{mV}$ as observed. Inward rectification is also a common feature of neuronal AChRs (Sargent, 1993; McGehee and Role, 1995). Although the incomplete space clamp limited the accuracy of the determination, it is clear that the current-voltage relationship was close to that expected for AChRs rather than for $\mathrm{K}^{+}$channels (Sargent, 1993). A role for $\mathrm{K}^{+}$efflux from postsynaptic cells in producing the presynaptic currents is also inconsistent with the different time courses and pharmacology of the pre- and postsynaptic responses to nicotine, as noted above.

The fact that bath-applied nicotine can trigger action potentials in the presynaptic terminal and elicit EPSCs in the postsynaptic cell illustrates the potential significance of the receptors for synaptic transmission. It is not known whether the AChRs responsible for generation of presynaptic action potentials in the calyx are presynaptic, i.e., close to the site of transmitter release, or preterminal, i.e., more distal on the preganglionic axon. The ability of nicotinic agonists to increase the frequency of spontaneous miniature postsynaptic events in the presence of TTX is often used to distinguish the two (Lena et al., 1993; McMahon et al., 1994a; McGehee et al., 1995; Alkondon et al., 1996; Bordey et al., 1996; Gray et al., 1996; Lena and Changeux, 1997). Preliminary experiments with the ciliary ganglion preparation indicate that bath-applied nicotine, as done here, desensitizes the postsynaptic AChRs too quickly to permit a reliable analysis of spontaneous EPSC frequency during nicotine exposure; this is true even when the basal frequency is increased by perfusion with 10 or 25 $\mathrm{mm} \mathrm{KCl}$ and 3 or $5 \mathrm{~mm} \mathrm{CaCl}_{2}$ (J. Coggan and D. Berg, unpublished observations). The fact that nicotine-induced currents can be recorded in calyces after TTX treatment, however, indicates that at least some of the receptors are likely to be presynaptic as opposed to preterminal.

The prolonged response of $\alpha$ Bgt-sensitive presynaptic currents was surprising in view of the rapid desensitization usually en- 
countered for $\alpha$ Bgt-sensitive AChRs on neuronal cell bodies (Zorumski et al., 1992; Alkondon and Albuquerque, 1993; Zhang et al., 1994, 1996). Rapid application of agonist ( $<5 \mathrm{msec})$ from a large bore pipette to dissociated ciliary ganglion neurons elicits a substantial $\alpha$ Bgt-sensitive response, whereas slower application $(\sim 100 \mathrm{msec})$ from a small bore pipette does not, probably because in the latter case, the $\alpha \mathrm{Bgt}$-sensitive response is slower, more desensitized, and overshadowed by the $\alpha$ Bgt-resistant response (Zhang et al., 1994). In the present experiments, the slow method of bath application and low agonist concentrations achieved at the site of recording may have combined to permit small but sustained responses to be detected in the absence of an overriding $\alpha$ Bgt-resistant response. $\alpha$ Bgt-sensitive neuronal AChRs desensitize more slowly when activated with low concentrations of agonist (Zhang et al., 1994), and a slowly advancing front of agonist might access new receptors at an appropriate pace to compensate for desensitizing receptors, thereby maintaining a detectable whole-cell response. It is not clear, however, whether such explanations can account fully for the sustained nicotinic responses observed in calyces.

An interesting possibility is that $\alpha$ Bgt-sensitive presynaptic AChRs containing the $\alpha 7$ gene product may be specialized to minimize desensitization. This would have the virtue of allowing the receptors to respond proportionately to agonist over a wide range of concentrations, durations, and frequency of exposure in vivo. It could also confer on receptors the obvious regulatory advantage of being able to influence calcium levels in the presynaptic terminal in a continuing manner despite chronic use of the circuit and repeated exposure to released ACh. Possible adaptations to achieve receptors with slow desensitization may include either an altered subunit composition in which other gene products are co-assembled with $\alpha 7$ subunits or long-lived posttranslational modifications of the receptors. A candidate for the latter would be the state of receptor phosphorylation in the presynaptic terminal, because phosphorylation is known to influence receptor desensitization in a number of systems (for review, see Huganir and Greengard, 1990).

The high concentrations of nicotine required and the lag time preceding initiation of the presynaptic response should not, in themselves, be taken as evidence that $\alpha \mathrm{Bgt}$-sensitive AChRs on nerve terminals in the ganglion are fundamentally different from those on cell bodies. Although the lag time might invite speculation about a requirement for second messengers or retrograde signals, it should be recalled that the superfusion system delivers agonist slowly and in dilute form to the ganglion surface. In fact, the rise times and decay rates of nicotine-induced responses even in the postsynaptic cells were delayed three orders of magnitude compared with those observed with rapid application of agonist to the isolated cells in vitro (Zhang et al., 1994). Nonetheless, it remains possible that presynaptic receptors have unique features that alter not only their rates of desensitization, as discussed above, but also their pharmacology and kinetics of activation. These will be important issues to examine in future work.

Combined evidence from biochemical, neuroanatomical, and electrophysiological studies suggests that presynaptic AChRs are widely distributed in the nervous system. Both $\alpha$ Bgt-sensitive (Henley et al., 1986; McGehee et al., 1995; Alkondon et al., 1996; Gray et al., 1996; Fu and Liu, 1997) and $\alpha$ Bgt-resistant AChRs (Clarke and Pert, 1985; Clarke et al., 1986; Swanson et al., 1987; Rapier et al., 1990; Grady et al., 1992; Lena et al., 1993; McMahon et al., 1994 a,b; Yu and Wecker, 1994; Lena and Changeux, 1997) have been implicated previously. The receptors appear capable of modulating release of multiple neurotransmitter types in the CNS and peripheral nervous system (Role and Berg, 1996, their references; Wonnacott, 1997). A key question is the endogenous source of transmitter activating the receptors. Identifying the conditions that stimulate presynaptic AChRs in vivo will be essential for understanding their role in synaptic modulation.

A likely source of transmitter for activation of presynaptic AChRs on cholinergic terminals, such as those in the ciliary ganglion, is the terminal itself. Released ACh could act on the presynaptic receptors, causing them to increase the total calcium load in the terminal by either of two mechanisms: direct influx through the receptors by virtue of their high relative permeability to calcium, or influx through voltage-gated calcium channels activated by membrane depolarizations that the receptors produce. Both mechanisms have been shown recently in thalamic nuclei to mediate transmitter release after activation of presynaptic AChRs (Lena and Changeux, 1997). The low-input impedance of presynaptic calyces in the ciliary ganglion, together with the absence of low-threshold calcium channels (Yawo and Momiyama, 1993), may hinder receptor activation of voltage-gated calcium channels and place greater weight on calcium influx through the receptors.

Increased calcium levels via AChRs on cholinergic terminals could exert positive feedback control, producing an effect similar to facilitation or post-tetanic potentiation. Both facilitation and post-tetanic potentiation occur in the ciliary ganglion (Martin and Pilar, 1964) and may help explain how synaptic transmission at calciform contacts on ciliary neurons can sustain firing rates of $100 \mathrm{~Hz}$ (Dryer and Chiappinelli, 1985). Multiple calcium sites are thought to be involved in such processes, in addition to the sites triggering secretion (Zucker, 1994). Accordingly, activation of presynaptic AChRs receptors may influence a range of presynaptic events, regardless of whether they are seen to produce increases in the frequency of spontaneous transmitter release. A different possibility for AChRs capable of triggering action potentials in the presynaptic structure is that the receptors may respond to transmitter released from adjacent axons during repetitive firing; this would encourage coordinate firing of whole populations.

A presynaptic location could enable even a few AChRs to exert significant modulation on synaptic signaling, as noted previously (McGehee et al., 1995; Gray et al., 1996). Moreover, the impact of the receptors could be amplified by synergistic effects with other signals reaching the terminal. For example, ATP and nicotine can act synergistically in promoting spontaneous release of neurotransmitter from spinal cord neurites in culture $(\mathrm{Fu}$ and Liu, 1997). ATP is co-released with ACh from cholinergic terminals, and presynaptic calyces in the ciliary ganglion have been shown to express ATP-activated, ligand-gated ion channels (Sun and Stanley, 1996). Judicious positioning of the receptors, together with synergistic actions with other signaling mechanisms, may explain how the relatively low numbers of AChRs in the nervous system mediate the broad range of functions and pathologies attributed to them (Dani and Heinemann, 1996).

\section{REFERENCES}

Alkondon M, Albuquerque EX (1993) Diversity of nicotinic acetylcholine receptors in rat hippocampal neurons. I. Pharmacological and functional evidence for distinct structural subtypes. J Pharmacol Exp Ther 265:1455-1473.

Alkondon M, Rocha ES, Maelicke A, Albuquerque EX (1996) Diversity of nicotinic acetylcholine receptors in rat brain. V. $\alpha$-Bungarotoxin- 
sensitive nicotinic receptors in olfactory bulb neurons and presynaptic modulation of glutamate release. J Pharmacol Exp Ther 278:1460-1471.

Bertrand D, Galzi JL, Devillers-Thiery A, Bertrand S, Changeux JP (1993) Mutations at two distinct sites within the channel domain M2 alter calcium permeability of neuronal $\alpha 7$ nicotinic receptor. Proc Natl Acad Sci USA 90:6971-6975.

Bordey A, Feltz P, Trouslard J (1996) Nicotinic actions on neurones of the central autonomic area in rat spinal cord slices. J Physiol (Lond) 497:175-187.

Clarke PBS, Pert A (1985) Autoradiographic evidence for nicotine receptors on nigrostriatal and mesolimbic dopaminergic neurons. Brain Res 348:355-358.

Clarke PBS, Hammill GS, Nadi NS, Jacobawitz DM, Pert A (1986) $3 \mathrm{H}$-nicotine and ${ }^{125} \mathrm{I}$ - $\alpha$-bungarotoxin receptors in the interpeduncular nucleus of rats. II. Effects of habenular deafferentation. J Comp Neurol 251:407-413.

Conroy WG, Berg DK (1995) Neurons can maintain multiple classes of nicotinic acetylcholine receptors distinguished by different subunit compositions. J Biol Chem 270:4424-4431.

Couturier S, Bertrand D, Matter J-M, Hernandez M-C, Bertrand S, Millar N, Valera S, Barkas T, Ballivet M (1990) A neuronal nicotinic acetylcholine receptor subunit $(\alpha 7)$ is developmentally regulated and forms a homo-oligomeric channel blocked by $\alpha$-Btx. Neuron 5:847-856.

Dani JA, Heinemann S (1996) Molecular and cellular aspects of nicotine abuse. Neuron 16:905-908.

De Lorenzo AJ (1960) The fine structure of synapses in the ciliary ganglion of the chick. J Biophys Biochem Cytol 7:31-36.

Dryer SE, Chiappinelli VA (1985) Properties of choroid and ciliary neurons in the avian ciliary ganglion and evidence for substance $\mathrm{P}$ as a neurotransmitter. J Neurosci 5:2654-2661.

El-Bizri H, Clarke PBS (1994) Blockade of nicotinic receptor mediated release of dopamine from striatal synaptosomes by chlorisondamine and other nicotinic antagonists administered in vitro. $\mathrm{Br} \mathrm{J}$ Pharmacol 111:406-413.

Fu W-M, Liu J-J (1997) Regulation of acetylcholine release by presynaptic nicotinic receptors at developing neuromuscular synapses. Mol Pharmacol 51:390-398.

Gerzanich V, Peng X, Wang F, Wells G, Anand R, Fletcher S, Lindstrom J (1995) Comparative pharmacology of epibatidine: a potent agonist for neuronal nicotinic acetylcholine receptors. Mol Pharmacol 48:774-782

Gotti C, Moretti M, Longhi R, Briscini L, Balestra B, Clementi F (1994) Expression of $\alpha$-bungarotoxin receptor subtypes in chick central nervous system during development. J Recept Res 14:335-346.

Gray R, Rajan AS, Radcliffe KA, Yakehiro M, Dani JA (1996) Hippocampal synaptic transmission enhanced by low concentrations of nicotine. Nature 383:713-716.

Grady S, Marks M, Wonnacott S, Collins A (1992) Characterization of nicotinic receptor-mediated ${ }^{3} \mathrm{H}$ dopamine release from synaptosomes prepared from mouse striatum. J Neurochem 59:848-856.

Henley JM, Lindstrom JM, Oswald RE (1986) Acetylcholine receptor synthesis in retina and transport to optic tectum in goldfish. Science 232:1627-1629.

Hess A (1965) Developmental changes in the structure of the synapse on the myelinated cell bodies of the chicken ciliary ganglion. J Cell Biol 25:1-19.

Huganir RL, Greengard P (1990) Regulation of neurotransmitter receptor desensitization by protein phosphorylation. Neuron 5:555-567.

Lena C, Changeux J-P (1997) Role of $\mathrm{Ca}^{2+}$ ions in nicotinic facilitation of GABA release in mouse thalamus. J Neurosci 17:576-585.

Lena C, Changeux J-P, Mulle C (1993) Evidence for "preterminal" nicotinic receptors on GABAergic axons in the rat interpeduncular nucleus. J Neurosci 13:2680-2688.

Martin AR, Pilar G (1963) Dual mode of synaptic transmission in the avian ciliary ganglion. J Physiol (Lond) 168:443-463.

Martin AR, Pilar G (1964) Presynaptic and post-synaptic events during post-tetanic potentiation and facilitation in the avian ciliary ganglion. J Physiol (Lond) 175:17-30.

McGehee DS, Role LW (1995) Physiological diversity of nicotinic acetylcholine receptors expressed by vertebrate neurons. Annu Rev Physiol 57:521-546.

McGehee D, Heath M, Gelber S, Role LW (1995) Nicotine enhance- ment of fast excitatory synaptic transmission in CNS by presynaptic receptors. Science 269:1692-1697.

McMahon LL, Yoon K-W, Chiappinelli VA (1994a) Electrophysiological evidence for presynaptic nicotinic receptors in the avian ventral lateral geniculate nucleus. J Neurophysiol 71:826-829.

McMahon LL, Yoon K-W, Chiappinelli VA (1994b) Nicotinic receptor activation facilitates GABAergic neurotransmission in the avian lateral spiriform nucleus. Neuroscience 59:689-698.

Rapier C, Lunt GG, Wonnacott S (1990) Nicotinic modulation of $\left[{ }^{3} \mathrm{H}\right]$ dopamine release from striatal synaptosomes: pharmacological characterization. J Neurochem 54:937-945.

Robinson SR, Hampson ECGM, Munro MN, Vaney DI (1993) Unidirectional coupling of gap junctions between neuroglia. Science 262:1072-1074.

Role LW, Berg DK (1996) Nicotinic receptors in the development and modulation of CNS synapses. Neuron 16:1077-1085.

Sargent PB (1993) The diversity of neuronal nicotinic acetylcholine receptors. Annu Rev Neurosci 16:403-443.

Schoepfer R, Conroy WG, Whiting P, Gore M, Lindstrom J (1990) Brain $\alpha$-bungarotoxin binding protein cDNAs and mAbs reveal subtypes of this branch of the ligand-gated ion channel gene superfamily. Neuron $5: 35-48$.

Seguela P, Wadiche J, Dineley-Miller K, Dani JA, Patrick JW (1993) Molecular cloning, functional properties, and distribution of rat brain $\alpha 7$ : a nicotinic cation channel highly permeable to calcium. J Neurosci 13:596-604.

Stanley EF (1989) Calcium currents in a vertebrate presynaptic nerve terminal: the chick ciliary ganglion calyx. Brain Res 505:341-345.

Stanley EF, Goping G (1991) Characterization of a calcium current in a vertebrate cholinergic presynaptic nerve terminal. J Neurosci 11:985-993.

Sun XP, Stanley EF (1996) An ATP-activated, ligand-gated ion channel on a cholinergic presynaptic nerve terminal. Proc Natl Acad Sci USA 93:1859-1863.

Swanson LW, Simmons DM, Whiting PJ, Lindstrom J (1987) Immunohistochemical localization of neuronal nicotinic receptors in the rodent central nervous system. J Neurosci 7:3334-3342.

Vaney DI (1991) Many diverse types of retinal neurons show tracer coupling when injected with biocytin or Neurobiotin. Neurosci Lett 125:187-190.

Vernallis AB, Conroy WG, Berg DK (1993) Neurons assemble acetylcholine receptors with as many as three kinds of subunits while maintaining subunit segregation among receptor subtypes. Neuron 10:451-464.

Vijayaraghavan S, Pugh PC, Zhang Z-w, Rathouz MM, Berg DK (1992) Nicotinic receptors that bind $\alpha$-bungarotoxin on neurons raise intracellular free $\mathrm{Ca}^{2+}$. Neuron 8:353-362.

Wilson Horch HL, Sargent PB (1995) Perisynaptic surface distribution of multiple classes of nicotinic acetylcholine receptors on neurons in the chicken ciliary ganglion. J Neurosci 15:7778-7795.

Wonnacott S (1997) Presynaptic nicotinic ACh receptors. Trends Neurosci 20:92-98.

Yawo H, Chuhma N (1994) $\omega$-Conotoxin-sensitive and resistant transmitter release from the chick ciliary presynaptic terminal. J Physiol (Lond) 477:437-448.

Yawo H, Momiyama A (1993) Re-evaluation of calcium currents in preand postsynaptic neurones of the chick ciliary ganglion. J Physiol (Lond) 460:153-172.

Yu ZJ, Wecker L (1994) Chronic nicotine administration differentially affects neurotransmitter release from rat striatal slices. J Neurochem 63:186-194.

Zhang Z-w, Vijayaraghavan S, Berg DK (1994) Neuronal acetylcholine receptors that bind $\alpha$-bungarotoxin with high affinity function as ligandgated ion channels. Neuron 12:167-177.

Zhang Z-w, Coggan JS, Berg DK (1996) Synaptic currents generated by neuronal acetylcholine receptors sensitive to $\alpha$-bungarotoxin. Neuron $17: 1231-1240$.

Zorumski CF, Thio LL, Isenberg KE, Clifford DB (1992) Nicotinic acetylcholine currents in cultured postnatal rat hippocampal neurons. Mol Pharmacol 41:931-936.

Zucker RS (1994) Calcium and short-term synaptic plasticity. Neth J Zool 44:495-512. 